\title{
Activating Strategies to Fossilization for English Learners in China
}

\author{
Dan Li \\ English Department, Foreign Language College, Hunan Agricultural University \\ PO box 410128, Changsha, Hunan, China \\ Tel: 86-731-463-8481_E-mail: dannylidan@126.com
}

\begin{abstract}
The paper attempts to explore the activating strategies to fossilizations for Chinese EFL learners. Fossilization, although always being ignored in China, still exerts its important role in blocking the EFL learning process for Chinese learners. To overcome this learning barrier, this paper is written to put forward the practical solutions to fossilization.
\end{abstract}

Keywords: Activating strategies, Fossilization, English learners in China

Fossilization, a common phenomenon in second language acquisition (SLA), refers to speakers of a particular native language persisting on using non-standard linguistic items, rules, and other subsystems relative to their particular target language.(Selinker, 1972) Although it first appeared in the category of SLA, the scholars still found its traits in EFL learning process and began to study it. (Chen Yaping, 1997; Chen Huiyuan, 1999) China, boasting of its largest population for EFL learning, can never avoid talking about this topic. But the situation here is hard to say.

\section{Most likely ignored problem in Chinese EFL teaching}

It does not mean that Chinese EFL teachers do not know the existence of fossilization. To the contrary, the authority academic database in China-CNKI reports that more than 150 papers are written by Chinese scholars, concerning with fossilization. But few of them really give attention to it in the teaching process.

Chinese EFL teaching always follows the model — textbook explanation. Under this misguidance, English teachers have to pay all the efforts to consider the fulfillment of textbook teaching. The teaching objectives are misled to the material learning, which is the criterion to evaluate a teacher's job, because all the tests here are knowledge-points-based instead of the competence-oriented. It is not worth time to overcome fossilization in such a teaching process. However, this ignorance of fossilization does not mean it won't exert its side-effects on Chinese EFL learners.

\section{Stumbling Blocks of Fossilization in EFL learning process}

In China, English learners, just like those from other countries, usually puzzle at the barriers they meet in fossilization. EFL learners in this traditional oriental country even have to take more challenges.

\subsection{Psychological barrier}

Psychological barrier is the largest problem to the learners. They don't show great interesting in English learning as before. After long years of study, most Chinese EFL learners learn English from their secondary or even primary school; they are no longer fascinated in English but taking it as a bone in the meat, because they seldom have the chance to use it in real situation.

Another psychological problem to the learners is the suspicion to their ability. Having paid a great deal of effort, they still do not see apparent improvement, and begin to doubt their own learning ability and even the necessity of continuous English learning course. Gradually the blocks of psychological barriers become the root of behavior barriers.

\subsection{Behavior barrier}

Influenced by those negative psychological elements from fossilization, Chinese EFL learners are confronted with more pressures from their behavior problems. Their oral English is still not as fluent as they expect. Most of them cannot express their thoughts freely. Their vocabularies are limited and expressions are shadowed in the past knowledge they learnt. Accuracy and decency is not good enough to be found a lot of repeated errors. Their writing works still follow Chinese English style. When they take reading and listening comprehension exercises, the results can never reach perfect. A lot of language learners seem lost in a standstill situation for long, which makes them lose their confidence and give up their routine practice. Those behavior barriers intensify the psychological barriers and lead to the cognitive barrier at last.

\subsection{Cognitive barrier}

Keith Johnson and Peter Tomlinson once suggested the possible causes of fossilization should be the cognitive learning models. (Zhang Xuemei, 2000) EFL cognitive model is different from L1 model. When L1 model is already latent in the mind, L1 cognitive mechanism is also generated. Since the mind is already occupied by the L1 cognitive mechanism, 
EFL learning has to rebuild a generating model for another language. China learners do not learn English until they can use Chinese fluently. Therefore, English, as a foreign language completely different from Chinese, is much more difficult to learn.

EFL cognitive environment is also different from L1, since it is lack of necessary communicative environment. In China, unlike in other English speaking countries, English is not an official language; it is not popularly used here. Learners can never enjoy an "immersion environment". Classroom teaching is the only way for them to learn English comprehensively.

Those subjective and objective barriers seem as an insurmountable mount in the way of Chinese EFL learning.

\section{Activating Strategies}

Impossible is nothing, fossilization still has its ways out. Although it seems uncrossable, the best way is always under the feet.

\subsection{Reinforcement of awareness of fossilization}

The most important thing for activating fossilization is to reinforce the learners' awareness to overcome their psychological barriers.

\section{1.1 Reinforcement of learners' awareness of fossilization}

True understanding to fossilization can arouse the learners' awareness. Chinese learners, unlike those from other countries, are less familiar with fossilization, since it is the most likely ignored problem here. When the learners are involving in it, they always puzzle at the present logjam situation. They do not see it is caused by a common phenomenon every EFL learners may experience. At this moment, the teacher's instant reminding may keep them sensible to the occurrence, and comfort their uneasy. In this way, at least, the learners could keep patience on their own performance in the fossilization. They will not lose their psychological control.

\subsubsection{Reinforcement of teachers' awareness}

Teacher is the next important person to bring attention to fossilization. For the teacher, more knowledge about fossilization seems helpful for them to take suitable teaching choice. When a teacher provides lecture, he could not promote the early attainment of fluency at the cost of accuracy. As to students' mistakes or errors, the teacher could give learners positive affective feedback. Therefore, keeping alert to fossilization in a teacher's heart is another solution to overcome the learners' psychological barriers.

\subsection{Intensification of learning motivation}

Motivation is the power of learning. During fossilization, the learners always lack of motivation. In order to change this negative situation, the EFL teachers may follow the way: Firstly, the EFL teacher should keep enthusiastic, earnest and responsible. A warm-hearted, open-minded and responsible teacher plays a key role in creating a relaxing and pleasant learning environment. As Finocchiaro(1981) has said, "motivation is the feeling nurtured primarily by the classroom teacher in the learning situation. The moment of truth, the enhancement of motivation, occurs when the teacher closes the classroom door, resets his students with a warm, welcoming smile, and proceeds to interact with various individual by making comments or asking questions which indicate personal concern." Secondly, the teacher should help learners take right attitudes toward the frustration from fossilization. Frustration mainly stems from difficulties and bad results of learning. If learners are afraid to make mistakes, their confidence of learning English will be weakened. Therefore, encouragement and error-tolerance from the teachers may help them solve problems and enhance their confidence. Thirdly, the teacher should keep the teaching contents interesting and original. In China, under the pressure of various English tests, many teachers attach much importance to the cultivation of learners' abilities to take examinations. They spend a lot of time in explaining sets of test paper. Such classroom settings are teacher-centered rather than learner-centered. In this case, the classroom seems dull and dry, which is hard to kindle the spark of learners' interest. If the teacher adopts vivid teaching contents with flexible teaching methods, the learners will much more like to take part in the classroom learning. At this time, colorful activities such as debates, role-plays, discussions or competitions and so on can be organized so as to arouse learners' interests. Finally, the teacher should urge the learners to preview the texts and finish assignments in time. Many students did not achieve good results, the main reason for which was that they did not preview the texts and prepare for the classroom activities. For example, in debates, many students seldom presented their opinions. It was due to the fact that they did not prepare for it in advance, so they seemed having nothing to say and lose interest gradually. In this case, it is quite necessary for the teacher to urge students to prepare for the assigned activities and preview texts in time so that students have something to say and want to say something in the class. In this way, the learners would have a sense of achievement and success. In turn, they would be more confident on learning English further and the onset of fossilization would be correspondingly reduced. 


\subsection{Avoidance of the first language interference}

Interference of first language is one of the leading reasons to fossilization. It has been learnt that many everlasting interlingua errors are concerned with the first language interference, such as omitting the third singular present tense final "s" and the relative pronouns before some special attributive clause, etc. To deal with these interferences, the teacher may adopt behaviorist viewpoints which suggest the language learning should be promoted when the learners take active and repeated responses to stimuli, which emphasize the importance of reinforcing learners' responses by rewarding target-based responses and correcting non-target-based ones. Therefore, when the students are taught certain grammatical rules or sentence structures related to first language interference, the teachers could use intensive techniques such as repetition or drills to overcome the interference and establish necessary new habits. For example, the teacher could ask students to repeat various sentences containing relative clauses after explaining specific rules about relative clauses. By doing so, the teacher can help learners reduce the interference from first language, and help them establish the habit for correct relative clauses. What's more, all students should be encouraged to read as much as possible English materials written by native writers. By reading, students can get exact meanings of words, and acquire the useful sentence structures to enhance their linguistic competences. Eventually, helping learners develop their language sense is another way to avoid the first language interference.

\subsection{Accumulation of foreign language input}

Quantity of input determines the quality of learning. It is evident that in China, not all EFL teachers speak English accurately with a native or near-native accent. Learners rarely hear standard conversational speech in class which is major source for EFL learners learning English. The minimal contact with standard language, they internalize many errors. Lack of the exposure to authentic input becomes one of the main causes of fossilization.

The large quantity of effective accurate input can help reduce fossilization. For language teachers, should adjust their own classroom language, in line with students' proficiency, to simpler or more difficult vocabulary and slower or faster speech while retaining natural rhythm and intonation. In the teaching process, the teacher should try hard to input some interesting and vivid materials to enrich the classroom activity and to arouse students' enthusiasm.

\subsection{Augment of language output}

In China, mechanical reciting is the main training for EFL learners. In fact, keeping those language points in mind is not a difficult task. But the key point is how to put the knowledge into practice.

More communicative activities seem more useful to enlarge language output. English teacher can organize English corners for once or more times a week. The given topic in English corner every week should be set in accordance with their course. Before English corner, the teacher demands students make adequate preparation for vocabulary, sentence structures, expressions and opinions. In the corner, the teacher can ask students to write down new words and expression and look up dictionary after they go back. Besides, holding speech contest is another way to activate the environment. At the same time students should have more chance to read original works, from which learners can study some well-known sentences and typical expressions in order to strengthen their identification and comprehension abilities.

All in all, fossilization, as a necessary phase in EFL learning, can never be ignored in China. To activate fossilization for those Chinese EFL learners, the above strategies are suggested to overcome its barriers psychologically, behaviously and cognitively.

\section{References}

Huiyuan Chen. (1999). A discussion on the sources of fossilization. Foreign Language Teaching and Research, 3, 37.

Yaping Chen. (1997). Psychological explanation and strategies to "Grade Two Phenomenon". Foreign Language Teaching and Research, 4, 60.

Finocchiaro, M. (1981). Motivation: Its crucial role in language learning. In: Hines and Rutherford. (Eds.), On TESOL' 81. Washington D.C.: TESOL.

Selinker, L. (1972). "Interlanguage", International Review of Applied Linguistics, 24.

Xuemei Zhang. (2000). A Cognitive Study of Fossilization. Journals of Foreign Languages, 4, 14. 